\title{
A patient who was burned in the operative field: a case report
}

\author{
Ameliyat alanında yanan bir hasta: Olgu sunumu
}

\author{
Soo-Ho CHUNG, Hae-Hyeog LEE, Tae-Hee KIM, Jeong-Sig KIM
}

\begin{abstract}
Operating room fires occur very rarely. Nevertheless, a disaster can complicate almost any kind of surgery. The majority of operating room fires result from the use of alcohol-based surgical preparation solutions, electro-surgical equipment, or flammable drapes in an oxygen-rich environment. We report a patient with an ovarian cyst and uterine myomas who suffered a flame burn while undergoing gynecological surgery.
\end{abstract}

Key Words: Fire; flame burn; operating room; alcohol-based surgical preparation solutions; electro-surgical equipment.
Ameliyat alanı yangınları oldukça nadirdir. Yine de, bir felaket, hemen hemen her türlü cerrahiyi güçleştirebilir. Ameliyat alanı yangınlarının çoğunluğu, oksijenden zengin bir ortamda alkol bazlı cerrahiye hazırlama solüsyonlarının, elektrikli cerrahi ekipmanın veya kolay tutuşan kumaşların kullanılmasından kaynaklanmaktadır. Biz, over kisti ve uterin miyomları nedeniyle jinekolojik cerrahi geçirirken alev yanığına maruz kalan hastayı sunuyoruz.

Anahtar Sözcükler: Alev; alev yanığı; ameliyathane; alkol bazlı cerrahi hazırlık solüsyonları; elektrikli cerrahi ekipman.
Fires in the operating room may start in a number of ways, although nonflammable anesthetics are thought to prevent fires in medical institutions. ${ }^{[1]}$ Operating room fires and burns are relatively rare, but such disasters can complicate almost any surgical procedure. In the United States, approximately 100 operating room fires are reported each year, although burns to the patient are not counted. ${ }^{[2,3]}$ When ignition sources such as alcohol-based surgical preparation solutions, electrosurgical equipment, and flammable drapes are used in an oxygen-rich environment, the risk of an operating room fire increases, and any burn is more severe in such conditions. Most burns in the operative field are chemical burns, which are difficult to extinguish.

We report herein a patient who suffered a burn during gynecological surgery for an ovarian cyst and uterine myomas.

\section{CASE REPORT}

A 47-year-old woman presented with a 10 -month history of amenorrhea and a four-day history of uterine bleeding. Her medical history was benign, and she had no previous surgery. She was referred to our department from a local clinic for evaluation and surgical management of a pelvic mass. The right ovary had a thick-walled cyst with a surrounding hematoma (a probable hemorrhagic corpus luteal cyst). There was a thin, egg-shell like calcified cystic mass in the posterior pelvic cavity. Laparoscopy was performed. At the time of surgery, a $6 \times 5-\mathrm{cm}$ cyst was noted in the right ovary and a $5 \times 5-\mathrm{cm}$ myoma-like mass was identified on the posterior uterus. A laparoscopic right ovarian cystectomy and myomectomy were performed.

The patient's surgeon commonly used a large amount of alcohol to clean and disinfect the operating field. While cleaning and preparing the skin, there was some bleeding from the trocar insertion site in the skin. When electro-surgical equipment was used by mistake, the alcohol on the patient's abdomen ignited. The drapes were used in an attempt to smother the fire, but the fire spread to the drapes (Fig. 1a) and triggered the fire alarm. It was difficult to extinguish the chemical fire, which required the use of fire extinguishers. The patient suffered a deep second-degree burn (Fig.

Department of Obstetrics and Gynecology, College of Medicine, Soonchunhyang University, Bucheon, Republic of Korea. 

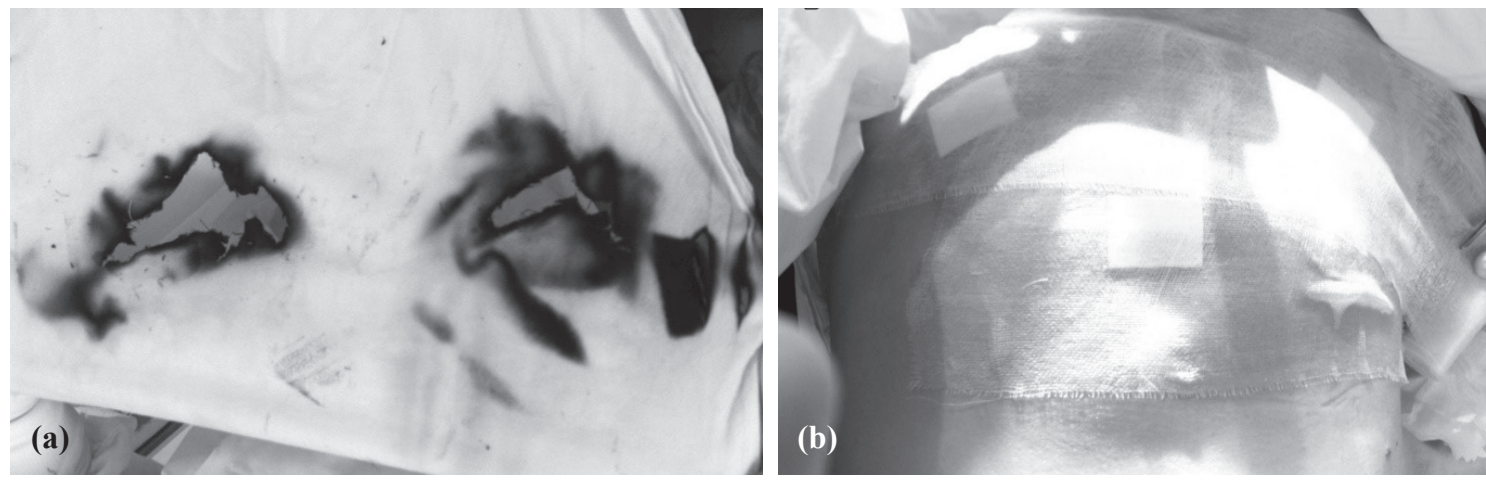

Fig. 1. Burn wound of the skin on the abdomen and burned drapery. (a) Burned drapery. (b) Wound with packed laparoscopy wound surrounded by deep second-degree burns.
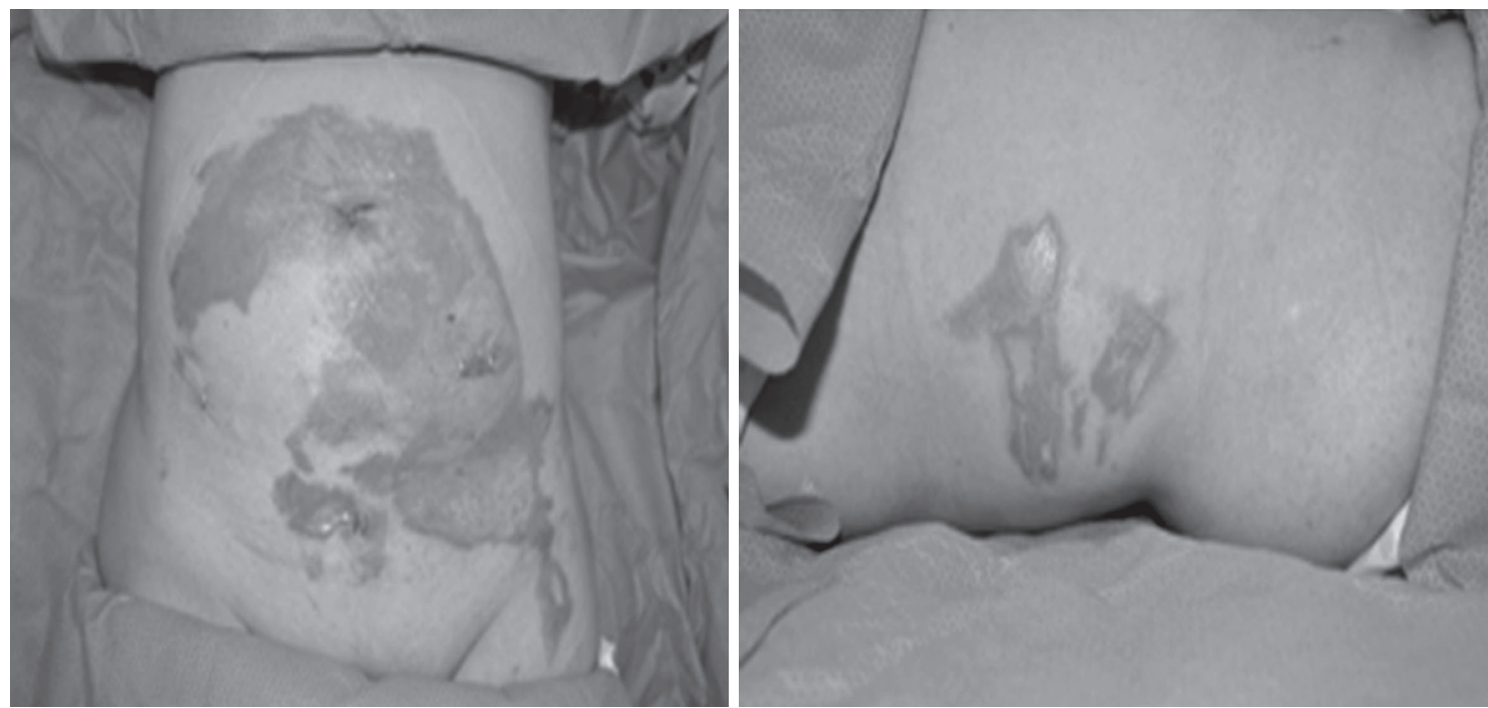

Fig. 2. Burn wound of the skin on the abdomen at postoperative 1 week.

1b). This was treated with daily burn dressings by plastic surgeons. Postoperatively, we prepared a risk management report. The patient was discharged one week after surgery (Fig. 2) and was followed at weekly intervals without other complications.

\section{DISCUSSION}

A few operating room fires have been reported. In the United States, the reported frequency is approximately 100 cases, 60 injuries, and two deaths per year. ${ }^{[2,4]}$ However, patient burns are not counted. Nearly $70 \%$ of these fires were related to the use of electro-surgical equipment; the oxygen-rich environment contributed to the fire and most of the burns were chemical burns. ${ }^{[5]}$ There is a significant risk of fire when alcohol-based surgical skin preparation solutions are used. Three conditions are needed for a fire outbreak: heat, fuel and an oxidizer. In operating room fires, the electro-surgical equipment most often ignites a flammable substance. The fuel is the alcoholbased surgical preparation solution and drapes. In an oxygen-rich environment, the presence of all three conditions can cause an object to burst into flames and burn intensely. ${ }^{[2,5,6]}$

It has been suggested that fires may be initiated by the ignition of the vapor generated from an antiseptic solution. The heat of the skin ensures that this is at high concentration near the operating site. The

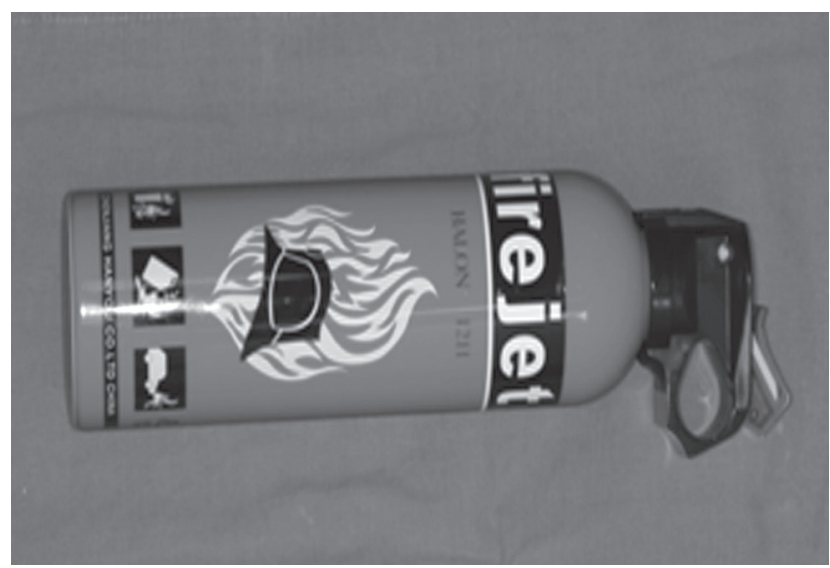

Fig. 3. Carbon dioxide fire extinguisher. 
Table 1. Fire safety protocol for the operating room

1. Be aware of the risk of ignition of volatile fluids, such as alcohol

2. Immediately pour cold water

3. Use a fire extinguisher

4. Examine the ignition point and other electrical equipment

5. Treat the patient's burns and prepare a risk management report

potential for fire is increased when the alcohol-based skin antiseptic is applied in ways that allow the solution to run off and collect into a pool on the skin or surgical drapes. ${ }^{[7]}$ As soon as the electro-cauterization instrument is activated, these vapors can ignite. Attention to these details demands increasing the required solution drying time. ${ }^{[8]}$ Operating room fires are uncommon, but have the potential to complicate surgical procedures disastrously. The risk of surgical fires can be minimized by avoiding situations in which all three conditions for a fire are present and by educating and training operating room personnel in fire hazards.

The speed of progression of a fire ignited by alcohol is faster compared with general fires. Dousing the fire site with water may be of help in diluting the concentrated alcohol. A carbon dioxide fire extinguisher (Fig. 3) can be used safely in the operative field, including a sterile field and the abdominal cavity.

There are five teaching points regarding fire prevention, which involve removing fuel and avoiding a fueloxidizer combination. First, it has been recommended that ${ }^{[1]} 10 \%$ povidone-iodine in alcohol solution, ${ }^{[2]}$ thimerosal in $50 \%$ alcohol solution, ${ }^{[3]} 70 \%$ chlorhexidine hand rub, and ${ }^{[4]}$ methanol or ethanol should not be used for skin cleaning in the operative field. Second, when using electro-surgical equipment, minimize the time it is used and use non-flammable equipment instead of flammable equipment. Third, when alcohol-based skin preparations have to be used, wait for at least 3 minutes for the solution to dry and wipe the skin with a cotton swab before draping the operative field.$^{[9]}$ Fourth, shave the skin and drape the patient with a clear plastic adhesive drape to prevent the collection of flammable vapors beneath the drapes. Fifth, when a fire breaks out, extinguish it using fire extinguishers. Surgeons must know the location of a fire extinguisher and how to use it properly. All surgeons and members of the operating team should be well informed regarding the fire safety protocol (Table 1).

\section{REFERENCES}

1. Macdonald AG. A brief historical review of non-anaesthetic causes of fires and explosions in the operating room. Br J Anaesth 1994;73:847-56.

2. Rinder CS. Fire safety in the operating room. Curr Opin Anaesthesiol 2008;21:790-5.

3. A clinician's guide to surgical fires. How they occur, how to prevent them, how to put them out. Health Devices 2003;32:5-24.

4. United States Fire Administration. Medical facility fires. Topical Fire Res Ser 2001;2.

5. Batra S, Gupta R. Alcohol based surgical prep solution and the risk of fire in the operating room: a case report. Patient Saf Surg 2008;2:10.

6. Spigelman AD, Swan JR. Skin antiseptics and the risk of operating theatre fires. ANZ J Surg 2005;75:556-8.

7. Prasad R, Quezado Z, St Andre A, O'Grady NP. Fires in the operating room and intensive care unit: awareness is the key to prevention. Anesth Analg 2006;102:172-4.

8. Tooher R, Maddern GJ, Simpson J. Surgical fires and alcohol-based skin preparations. ANZ J Surg 2004;74:382-5.

9. Patel R, Chavda KD, Hukkeri S. Surgical field fire and skin burns caused by alcohol-based skin preparation. J Emerg Trauma Shock 2010;3:305. 